\title{
PELATIHAN MENYUSUN TES UJI KOMPETENSI UNTUK MASTER PENGUJI KURSUS DI KEMENTERIAN PENDIDIKAN DAN KEBUDAYAAN
}

\author{
TRAINING IN PREPARATION OF COMPETENCY TEST FOR MASTER COURSE \\ EXAMINERS IN THE MINISTRY OF EDUCATION AND CULTURE \\ ${ }^{1)}$ Riyan Arthur, ${ }^{2}$ Daryati, ${ }^{3)}$ Ahmad Marzuq, ${ }^{4)}$ Laurika Kusuma Dewi \\ ${ }^{1,2)}$ Pendidikan Vokasional Konstruksi Bangunan, Fakultas Teknik \\ ${ }^{3)}$ Pendidikan Bahasa Arab Fakultas Bahasa dan Seni \\ Universitas Negeri Jakarta, Kampus A UNJ Gd. DE Jalan Rawamangun Muka Jakarta Timur \\ ${ }^{4)}$ Pascasarjana UHAMKA \\ Jalan Warung Jati Barat Kalibata, Jakarta Selatan \\ Email: arthur@unj.ac.id
}

\begin{abstract}
ABSTRAK
Perubahan berbagai bidang pada era milenial menyebabkan menyebabkan pendidikan formal tak lagi sanggup mengikuti tuntutan ini. Kondisi ini menyebabkan minat masyarakat terhadap pendidikan kursus semakin meningkat. Peningkatan kompetensi berbagai bidang melalui pendidikan kursus harus diimbangi dengan peningkatan kemampuan evaluasi para Master Penguji, terutama dalam menyusun tes uji kompetensi. Kegiatan ini bertujuan untuk meningkatkan kemampuan menyusun tes uji kompetensi bagi master penguji kursus Lembaga Sertifikasi Kompetensi (LSK) di bawah naungan Direktorat Kursus dan Pelatihan Kemdikbud sebagai upaya dalam memperbaiki tes objektif dan praktik uji kompetensi kursus sehingga dapat meluluskan tenaga kerja siap pakai. Metode yang digunakan dalam pelatihan adalah ceramah, brainstorming, tanya jawab, workshop, penugasan dan demonstrasi langsung. Berdasarkan data yang ada dan setelah dilakukan evaluasi pada dasarnya penguasaan konsep evaluasi, penilaian dan pengukuran master penguji kursus cukup baik dengan rata-rata 76,60 untuk tes teori dan 74, 55 untuk tes praktik, namun masih perlu pembinaan yang berkelanjutan terutama dalam menyusun kalimat pada pokok soal, menyusun pilihan jawaban dan menurunkan indikator menjadi butir yang sesuai.
\end{abstract}

Kata kunci: Pelatihan; Penyusunan Tes; Uji Kompetensi; Penguji; Kursus

\begin{abstract}
Changes in various fields in the millennial era have caused formal education to no longer be able to keep up with this demand. This condition causes the interest of the community towards course education increasing. Increasing the competency of various fields through education courses must be balanced with an increase in the evaluation skills of the Master Examiners, especially in preparing the competency test. This activity aims to improve the ability to compose competency test tests for master examiners of the Competency Certification Institute (LSK) courses under the auspices of the Ministry of Education and Training Directorate of Ministry of Education and Culture in an effort to improve the objective tests and practice competency test courses so that they can pass the workforce ready for use. The methods used in training are lectures, brainstorming, questions and answers, workshops, assignments and live demonstrations. Based on the available data and after the evaluation, basically mastery of the concept of evaluation, assessment, and measurement of the master examiner of the course is quite good with an average of 76.60 for the theory test and 74,55 for the practical test, but it still needs ongoing coaching, especially in preparing sentences on the subject matter, arrange the choice of answers and reduce the indicators to the appropriate items.
\end{abstract}

Keywords: Training; Test Preparation; Competence test; Examiner; Courses

Submitted : 29 September 2019 Revision : 29 Oktober 2019 Accepted : 20 Februari 2020 


\section{PENDAHULUAN}

Kebutuhan masyarakat terhadap kompetensi melalui kursus dan pelatihan terus mengalami peningkatan, baik dalam jumlah maupun jenis kursus yang dibutuhkan (Arthur \& Daryati, 2019) Perubahan di era milenial yang sedemikian cepatnya mendorong variasi bidang sehingga banyak hal yang terdapat di pendidikan formal tak lagi sanggup mengikutikeadaan saat ini.

Kursus dan pelatihan merupakan alternatif tercepat dan paling tepat untuk menghadapi masalah di atas. Fokus dan kecepatan dalam pembelajaran merupakan kelebihan yang tidak dimiliki jalur formal. Selain itu, adaptasi dan variasi kursus yang dapat dilakukan secara responsif menjadi kunci bagi masyarakat dalam menghadapi tantangan zaman tersebut (Yulius, Isran, WP, \& Anugerah, 2017) seperti yang terlihat pada gambar di bawah ini:

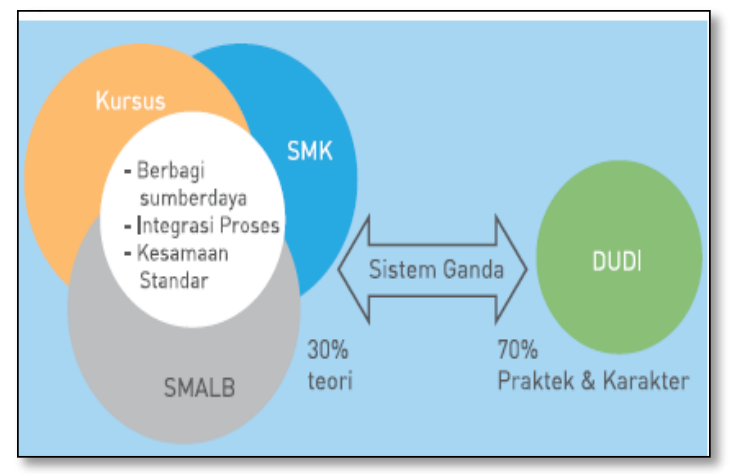

Gambar 1. Kualitas Rencana Integrasi Pendidikan Vokasi Kemendikbud Sumber: (Yulius, et al., 2017)

Penyelenggaraan kursus yang berbasis pada kompetensi di Lembaga Kursus dan Pelatihan (LKP) hendaknya juga dibarengi dengan kualitas lulusan yang baik (Hadi, 2018). Oleh karena itu, dari mulai kurikulum, instruktur (pendidik), penguji bahkan master penguji mempunyai peran yang strategis (Sujanto, 2016). Pelaksanaan uji kompetensi kursus pun hendaknya adaptif dengan perubahan zaman yang serba digital saat ini.

Jumlah kursus yang sekarang meningkat menjadi 38 jenis bidang kursus memerlukan uji kompetensi. Sedangkan uji kompetensi kursus terbagi atas 2, yaitu: ujian teori dan ujian praktik. Ujian teori lebih menekankan kepada pengetahuan baik materi, sikap maupun pengetahuan tentang prosedur praktik. Sedangkan ujian praktik lebih menekankan pada sikap kerja dan keterampilan dari materi kursus yang telah dilaksanakan. Master penguji kursus memiliki posisi kunci dalam pelaksanaan uji kompetensi ini. Oleh karena itu, dibutuhkan master penguji yang kompeten dalam hal ilmu pengukuran, penilaian dan evaluasi (Herlinda, Hidayat, \& Djumena, 2018).

Di sisi lain instrumen uji kompetensi selayaknya memiliki kualitas yang tinggi, baik dari konstruksi, materi maupun bahasa (Maulana, Arthur, \& Daryati, 2019; Prasetyo, Daryati, \& Arthur, 2019). Pada kondisi yang semacam ini, sangat dibutuhkan master-master penguji kursus yang handal, karena kualitas uji kompetensi secara tidak langsung ditentukan oleh butir tes, proses dan mekanisme pengawasannya.

Koneksi antara LKP, LSK dan hasil pembelajaran terkait kursus sangat penting untuk memastikan kompetensi peserta didik tersebut, meskipun ada aspek yang lebih luas untuk dipertimbangkan ketika menilai kualitas penilaian, terutama ketika penilaian tersebut terkait dengan kompetensi untuk berlatih secara profesional. Begitu banyak hal yang harus dikuasai oleh (master) penguji (Schaap, Baartman, \& de Bruijn, 2012).

Argumentasi bahwa uji kompetensi individu mungkin tidak dapat memenuhi semua indikator kualitas kursus secara keseluruhan harus menjadi tantangan tersendiri bagi seluruh perangkat kursus dalam membuktikannya secara akademis. (Baird, Gamble \& Sidebotham, 2016). Kegiatan pelatihan ini bertujuan agar dapat meningkatkan kompetensi master penguji kursus.

\section{METODE}

Metode yang digunakan dalam kegiatan pelatihan ini antara lain dengan ceramah, brainstorming, diskusi, tanya jawab, workshop, penugasan, proyek dan demonstrasi langsung. Metode-metode tersebut dikembangkan sesuai dengan situasi dan kondisi yang berkembang dan secara simultan serta berkesinambungan.

Sasaran pada kegiatan pembinaan kemampuan menyusun tes uji kompetensi adalah master penguji kursus sebanyak 28 
orang master penguji dari 19 bidang kursus di wilayah Jabodetabek. Strategi yang bisa dilakukan dalam menyusun tes uji kompetensi dapat dijabarkan sebagai berikut:.

1. Menyusun tes objektif teori berbasis daring (online) berdasarkan kaidah penyusunan butir tes yang terdiri dari 3 dimensi dan 18 indikator melalui penyampaian langsung, praktik dan penugasan.

2. Mengembangkan rubrik penilaian tes praktik sesuai dengan Standar Kompetensi Lulusan (SKL) dan kaidah pengembangan rubrik tes praktik melalui penyampaian langsung, praktik dan penugasan.

Target yang akan dicapai dalam pelaksanaan kegiatan ini adalah meningkatnya kemampuan master penguji kursus dalam pengetahuan, pemahaman dan keterampilan dalam menyusun tes uji kompetensi baik teori maupun praktik. yaitu:

Kegiatan pelatihan ini terbagi atas 4 tahap,

1. Tahap pemberian wawasan, pengertian dan pemahaman tentang konsep evaluasi, penilaian dan pengukuran kepada master penguji kursus yang mengacu pada uji kompetensi kursus.

2. Tahap penyampaian kaidah-kaidah tes objektif (teori) berbasis daring (online) dan pengembangan rubrik tes praktik dalam uji kompetensi kursus.

3. Tahap Pendampingan dalam penyusunan butir tes objektif (teori) berbasis daring (online) dan pengembangan rubrik tes praktik dalam uji kompetensi kursus.

4. Tahap evaluasi hasil dari penyusunan butir tes objektif (teori) berbasis daring (online) dan rubrik penilaian tes praktik yang telah dibuat oleh master penguji.

Untuk menyelesaikan masalah, maka dibutuhkan narasumber dengan kepakaran tertentu. Dalam pelatihan master penguji ini, kriteria dari narasumber adalah:

1. Ahli dalam bidang pengukuran, penilaian dan evaluasi (program studi S2/S3 PEP $\mathrm{UNJ}$ ).

2. Ahli dalam bidang vokasi dan kejuruan (FT UNJ).

3. Ahli dalam tata bahasa (FBS UNJ)
Adapun bidang kursus yang terlibat sebagai berikut:

Tabel 1. Bidang kursus dan pelatihan yang ikut serta dalam pelatihan

\begin{tabular}{ll}
\hline No & Bidang Kursus \\
\hline 1 & Bahasa Inggris \\
\hline 2 & Ekspor Impor \\
\hline 3 & Fotografi \\
\hline 4 & Hantaran \\
\hline 5 & Mengemudi Kendaraan Bermotor \\
\hline 6 & Otomotif Kendaraan Ringan \\
\hline 7 & Otomotif Sepeda Motor \\
\hline 8 & Pekarya Kesehatan \\
\hline 9 & Pengasuh Anak \\
\hline 10 & Penyiaran \\
\hline 11 & Perhotelan dan Kapal Pesiar \\
\hline 12 & Perpajakan \\
\hline 13 & Petaman \\
\hline 14 & Pijat Tradisional \\
\hline 15 & Refleksi \\
\hline 16 & Sekretaris \\
\hline 17 & Seni Merangkai Bunga dan Desain Floral \\
\hline 18 & Tata Boga \\
\hline 19 & Tata Busana \\
\hline & \\
\hline
\end{tabular}

\section{HASIL DAN PEMBAHASAN}

Kegiatan Pengabdian Masyarakat ini berkonsep kemitraan antara Direktorat Kursus dan pelatihan Kementerian Pendidikan dan Kebudayaan (Kemdikbud), seluruh Lembaga Sertifikasi Kompetensi (LSK) di bawah naungan Kemdikbud dengan Program Studi S1 Pendidikan Vokasional Konstruksi Bangunan Fakultas Teknik Universitas Negeri Jakarta.

Sebelum pelatihan dimulai dilakukan koordinasi antara Direktorat Kursus dan pelatihan Kemdikbud, Lembaga Sertifikasi Kompetensi (LSK) dan pihak Fakultas Teknik Universitas Negeri Jakarta (FT UNJ). Koordinasi dimaksudkan agar terjadi sinergi antara Universitas Negeri Jakarta dengan Kemdikbud dalam hal ini direktorat pembinaan kursus dan pelatihan. LSK sebagai tempat bernaung master penguji, merupakan salah satu lembaga yang bermitra langsung dengan direktorat kursus dan pelatihan. Oleh karena itu, dengan berkoordinasi dengan direktorat kursus 
dan pelatihan serta LSK sebagai mitra dapat membantu berjalannya kegiatan ini.

Pelaksanaan kegiatan pelatihan dilakukan dalam 4 sesi, yaitu: 1) materi konsep dasar evaluasi, 2) teori dan praktik penyusunan butir tes objektif berbasis daring, 3) teori dan praktik penyusunan rubrik tes praktik, 4) praktik penyusunan butir tes objektif berbasis daring dan rubrik tes praktik. Setelah 3 hari dilakukan pelatihan, maka pada tanggal 27 Februari 2019, kegiatan resmi ditutup.

Adapun hasil penyusunan tes objektif teori dan praktik berturut-turut setelah 2 bulan peserta kembali ke instansi asal adalah sebagai berikut:

Tabel 2. Hasil Penilaian Tes Objektif Teori Pelatihan Master Penguji

\begin{tabular}{|c|c|c|c|c|}
\hline \multirow{2}{*}{ Peserta } & \multicolumn{3}{|c|}{ Dimensi } & \multirow{2}{*}{ Skor } \\
\hline & materi & Konstruksi & Bahasa & \\
\hline 1 & 15 & 45 & 20 & 80 \\
\hline 2 & 15 & 45 & 20 & 80 \\
\hline 3 & 15 & 45 & 20 & 80 \\
\hline 4 & 15 & 45 & 20 & 80 \\
\hline 5 & 15 & 45 & 20 & 80 \\
\hline 6 & 15 & 45 & 20 & 80 \\
\hline 7 & 15 & 45 & 20 & 80 \\
\hline 8 & 15 & 45 & 20 & 80 \\
\hline 9 & 15 & 45 & 20 & 80 \\
\hline 10 & 15 & 45 & 20 & 80 \\
\hline 11 & 13 & 42 & 20 & 75 \\
\hline 12 & 15 & 45 & 20 & 80 \\
\hline 13 & 0 & 0 & 0 & 0 \\
\hline 14 & 15 & 45 & 20 & 80 \\
\hline 15 & 15 & 44 & 20 & 79 \\
\hline 16 & 15 & 45 & 20 & 80 \\
\hline 17 & 15 & 45 & 20 & 80 \\
\hline 18 & 15 & 45 & 20 & 80 \\
\hline 19 & 15 & 44 & 20 & 79 \\
\hline 20 & 14 & 44 & 20 & 78 \\
\hline 21 & 13 & 45 & 20 & 78 \\
\hline 22 & 15 & 45 & 20 & 80 \\
\hline 23 & 15 & 45 & 20 & 80 \\
\hline 24 & 14 & 44 & 20 & 78 \\
\hline 25 & 15 & 45 & 20 & 80 \\
\hline
\end{tabular}

\begin{tabular}{|c|c|c|c|c|}
\hline \multirow{2}{*}{ Peserta } & \multicolumn{3}{|c|}{ Dimensi } & \multirow{2}{*}{ Skor } \\
\cline { 2 - 5 } & materi & Konstruksi & Bahasa & \\
\hline 26 & 15 & 43 & 20 & 78 \\
\hline 27 & 15 & 45 & 20 & 80 \\
\hline 28 & 15 & 45 & 20 & 80 \\
\hline $\begin{array}{c}\text { Jumlah } \\
\begin{array}{c}\text { Rata- } \\
\text { rata }\end{array}\end{array}$ & 14,3 & 43,071 & 19,286 & 76,60 \\
\hline $\begin{array}{c}\text { Skor } \\
\text { max }\end{array}$ & 15 & 45 & 20 & 80 \\
\hline
\end{tabular}

Berdasarkan data di atas, dapat digambarkan bahwa kemampuan rata-rata master penguji dalam hal menyusun butir tes objektif yang bersifat materi teori sudah cukup baik. Hal ini diperkuat dengan skor rata-rata yang mencapai 76,60 dari skor maksimum 80 .

Skor minimum yang diperoleh dari tugas proyek ini sebesar 75 dan ada 1 orang peserta yang tidak mengumpulkan. Adapun sebanyak 20 orang peserta mendapat skor sempurna (80). Hal ini menandakan bahwa sebagian besar peserta dapat memahami dan mempraktikkan materi pelatihan pada sesi menyusun tes objektif teori berbasis daring.

Kondisi ini selaras dengan hasil penelitian Hadi (2018) yang menemukan bahwa penerapan kurikulum terutama pada standar penilaian kursus yang sudah berhasil dengan kategori baik. Hal ini pun dibuktikan pula oleh Sujanto(2016) dengan melakukan kajian terhadap kemitraan kursus dengan dunia usaha dan industri (DUDI) yang ternyata lulusan LKP banyak yang telah menembus pasar kerja dalam dan luar negeri. Artinya para pengajar di kalangan kursus pada dasarnya memiliki kemampuan yang sesuai dengan kebutuhan pasar kerja.

Kelemahan peserta umumnya terletak pada penyusunan konstruksi butir, terutama pada keselarasan dan homogenitas opsi jawaban, pengecoh yang kurang berfungsi, dan pokok soal yang kurang tajam. Kelemahan selanjutnya yang paling menonjol adalah ketidaksesuaian materi dengan indikator yang akan diukur, hal ini akan berdampak pada rendahnya validitas. 
Tabel 3. Hasil Penilaian Tes Praktik Pelatihan

\begin{tabular}{|c|c|}
\hline \multicolumn{2}{|c|}{ Master Penguji } \\
\hline No. & Skor \\
\hline 1 & 100 \\
\hline 2 & 0 \\
\hline 3 & 100 \\
\hline 4 & 50 \\
\hline 5 & 50 \\
\hline 6 & 50 \\
\hline 7 & 100 \\
\hline 8 & 0 \\
\hline 9 & 75 \\
\hline 10 & 100 \\
\hline 11 & 50 \\
\hline 12 & 100 \\
\hline 13 & 100 \\
\hline 14 & 100 \\
\hline 15 & 100 \\
\hline 16 & 25 \\
\hline 17 & 87,5 \\
\hline 18 & 87,5 \\
\hline 19 & 87,5 \\
\hline 20 & 87,5 \\
\hline 21 & 75 \\
\hline 22 & 100 \\
\hline 23 & 87,5 \\
\hline 24 & 100 \\
\hline 25 & 100 \\
\hline 26 & 75 \\
\hline 27 & 12,5 \\
\hline 28 & 87,5 \\
\hline Jumlah & 2087,5 \\
\hline Rata-rata & 74,55 \\
\hline
\end{tabular}

Berdasarkan hasil penilaian pada penyusunan rubrik tes praktik pada uji kompetensi ini, didapatkan skor rata-rata 74,55. Artinya, secara keseluruhan kompetensi master penguji dalam menyusun rubrik tes masih kurang memuaskan di samping adanya 1 orang peserta yang tidak mengumpulkan.

Skor minimum yang didapatkan hanyalah 12,5 sedangkan skor maksimum yang didapatkan sebesar 100 atau sempurna. Hal ini menandakan bahwa kesenjangan yang terjadi pada master penguji begitu jauh. Namun demikian adanya 16 peserta mendapatkan skor di atas 80 di mana 11 diantaranya adalah sempurna merupakan fakta bahwa pada dasarnya kompetensi mayoritas master penguji sudah cukup baik dalam penyusunan rubrik tes praktik ini. Oleh karena itu, perlu dipertimbangkan untuk mengadakan pelatihan khusus terkait penyusunan rubrik tes praktik dan juga penyamaan persepsi tentang rubrik yang akan digunakan dalam uji kompetensi kursus.

Pada penyusunan rubrik ini pada dasarnya juga mirip dengan penyusunan butir tes objektif. Peserta banyak menggunakan 2 ukuran dalam satu butir, atau dengan kata lain butir tes banyak bermakna ganda. Selain itu, kendala yang biasanya terjadi pada rubrik juga terlihat yaitu pemberian skor atau pembobotan yang kurang proporsional.Namun demikian, kelemahan-kelemahan itu masih dalam batasbatas toleransi. Hal ini dapat dilihat banyaknya yang mendapat skor sempurna.

Hasil ini menunjukkan bahwa pada dasarnya dalam kompetensi, para guru, pelatih atau pengajar telah memiliki kompetensi yang baik. Hanya saja masih diperlukan pembinaan. Sama halnya dengan para pengajar pada Diklat Kemdikbud yang biasa disebut Widyaiswara, kendala yang muncul kurang lebih sama, yaitu kelemahan dalam menyusun butir tes (Arthur, 2018).

Bukan hanya pada penentuan kompetensi lembaga kursus, bahkan pada instrumen tes kompetensi selevel Kementerian Pekerjaan Umum (kemen PU) pun kualitas yang kurang baik masih mengemuka dengan nyata. Hasil penelitian menunjukkan bahwa instrumen uji kompetensi pada pelatihan bata (Maulana et al., 2019) dan plesteran (Prasetyo et al., 2019) masih jauh dari standar sebuah instrumen kompetensi.

Adapun kelemahan-kelemahan dalam pelatihan semacam ini pada dasarnya nyaris sama dengan pelatihan-pelatihan terdahulu yaitu kurang adanya jaminan keberlanjutan baik pelatihan di bidang pertanian seperti kelapa (Hendarmin, Kartika, \& Pebrianti, 2018), VCO (Ibrahim, Azis, \& Akolo, 2019), maupun dibidang kehidupan sehari-hari seperti reparasi listrik serta alat rumah tangga (Sardi \& Pulungan, 2019) dan juga di bidang pendidikan 
seperti pelatihan guru (Mansyur \& Akidah, 2018).

\section{SIMPULAN}

Berdasarkan hasil pelaksanaan pengabdian masyarakat dalam bentuk pelatihan yang telah diuraikan di atas, setelah dilakukan evaluasi pada dasarnya penguasaan konsep evaluasi, penilaian dan pengukuran master penguji kursus secara keseluruhan sudah cukup baik, namun masih perlu pembinaan yang berkelanjutan.

Dalam hal mekanisme penilaian dalam uji kompetensi, masih terdapat perbedaan yang nyata antar master penguji kursus bidang satu dengan bidang yang lainnya. Artinya, belum adanya titik temu yang menyeluruh, dikarenakan begitu beragamnya bentuk kursus, latar belakang master penguji dan karakteristik dari kursus tersebut. Pemahaman dan kemampuan menerapkan dalam penyusunan tes objektif teori berbasis daring, master penguji kursus sudah memenuhi standar yang ditentukan secara umum. Namun demikian, masih perlu ditingkatkan serta dilakukan pembinaan yang berkelanjutan.

Dalam hal pemahaman dan kemampuan menerapkan tes praktik yang berbentuk rubrik, terdapat kesenjangan yang cukup jauh antara yang benar-benar mampu dan yang masih perlu dibimbing. Oleh karena itu, perlu adanya pelatihan khusus terkait pemahaman, penyusunan dan penerapan dalam menyusun rubrik.

\section{UCAPAN TERIMA KASIH}

Diucapkan terima kasih kepada Direktorat Pembinaan Kursus dan Pelatihan Kemdikbud, para ketua LSK, dan LKP yang telah memberikan ruang dan kesempatan yang begitu baik. Begitu juga kepada Dekan FT UNJ beserta rekan-rekan dosen yang tidak dapat disebutkan satu per satu.

\section{DAFTAR PUSTAKA}

Arthur, R. (2018). Evaluasi Program Diklat Karya Tulis Ilmiah untuk Widyaiswara Pusbangtendik Kemdikbud. Jurnal Penelitian Dan Evaluasi Pendidikan, 22(1), 35-48. https://doi.org/10.21831/pep.v22i1.16749
Arthur, R., \& Daryati. (2019). A Need Assessment on Competency Certification of Construction Workers in Indonesia. In KnE Social Sciences (Vol. 3, p. 162). https://doi.org/10.18502/kss.v3i12.4082

Baird, K., Gamble, J., \& Sidebotham, M. (2016). Assessment of the quality and applicability of an e-portfolio capstone assessment item within a bachelor of midwifery program. Nurse Education in Practice, 20, 11-16. https://doi.org/10.1016/j.nepr.2016.06.00 7

Hadi, S. (2018). Evaluasi implementasi kurikulum berbasis kompetensi pada lembaga kursus dan pelatihan (LKP) program otomotif DIY. Jurnal Pendidikan Vokasi, 2(2), 267-283. https://doi.org/10.21831/jpv.v2i2.1036

Hendarmin, H., Kartika, M., \& Pebrianti, W. (2018). Pelatihan dan Pendampingan Pengolahan Komoditi Kelapa. JPPM (Jurnal Pengabdian Dan Pemberdayaan Masyarakat), 2(1), 1-6. Retrieved from http://jurnalnasional.ump.ac.id/index.php /JPPM/article/view/1706/1860

Herlinda, S., Hidayat, S., \& Djumena, I. (2018). Manajemen Pelatihan Hantaran dalam Meningkatkan Kecakapan Hidup Warga Belajar di Lembaga Kursus dan Pelatihan. Journal of Nonformal Education and Community Empowerment, 1(1), 1-9. https://doi.org/10.15294/pls.v1i1.14758

Ibrahim, P. S., Azis, R., \& Akolo, I. R. (2019). Pelatihan Pembuatan Vco Untuk Meningkatkan. JPPM (Jurnal Pengabdian Dan Pemberdayaan Masyarakat), 3(2).

Mansyur, U., \& Akidah, I. (2018). Peningkatan Kompetensi Profesional Guru MTs DDI Padanglampe Kabupaten Pangkep Melalui Pelatihan Penulisan Karya Tulis Ilmiah. Jurnal Pengabdian Dan Pemberdayaan Masyarakat, 2(2), 273278.

https://doi.org/10.30595/jppm.v2i2.2589

Maulana, I., Arthur, R., \& Daryati, D. (2019). Kualitas Tes Kompetensi Tukang Aci dan Plesteran Berdasarkan KKNI. Jurnal Pendidikan Teknologi Dan Kejuruan, 
$16(2)$,

$149-158$.

https://doi.org/10.23887/jptk-

undiksha.v16i2.17141

Prasetyo, M. E., Daryati, D., \& Arthur, R. (2019). Quality of the Skill Instrument Install Brick Based on the Indonesian National Qualification Framework (KKNI). Jurnal Taman Vokasi, 7(1), 1822. https://doi.org/10.30738/jtv.v7i1.4769

Sardi, J., \& Pulungan, A. B. (2019). Pelatihan Reparasi dan Perawatan Alat Listrik Rumah Tangga untuk Pemuda Pesisir. JPPM (Jurnal Pengabdian Dan Pemberdayaan Masyarakat), 3(1), 1-4. Retrieved from http://jurnalnasional.ump.ac.id/index.php /JPPM/article/view/2396/2428

Schaap, H., Baartman, L., \& de Bruijn, E.
(2012). Students' Learning Processes during School-Based Learning and Workplace Learning in Vocational Education: A Review. Vocations and Learning, 5(2), 99-117. https://doi.org/10.1007/s12186-0119069-2

Sujanto, A. (2016). Pengembangan Kemitraan Lembaga Kursus Dan Pelatihan (LKP) Dengan Dunia Usaha Dan Dunia. Infokam, (1), 59-65.

Yulius, Isran, M., WP, M., \& Anugerah, B. (2017). Kebijakan Pengembangan Vokasi di Indonesia 2017-2045. (F. Aritonang \& S. Gabriel, Eds.). Jakarta. 